\title{
Graph-Analytical Method of the Regional Transport Complex Control System Optimizing
}

\author{
Murat Bedanokov ${ }^{1}$, Yusuf Guketlev ${ }^{1 *}$, Yana Tkacheva ${ }^{1}$, and Natalia Mashinina ${ }^{1}$ \\ ${ }^{1}$ Maikop State Technological University, 191 Pervomajskaya, Maikop, 385000, Russia
}

\begin{abstract}
A graph-analytical optimization model of the formation of the regional transport complex management system (RTC) is presented. The model allows analyzing and implementing priority selection in the formation of effective control schemes for the RTK management. It allows taking into account socio-economic characteristics of a specific region when carrying out comparative analysis of the existing management models. The model is based on the ideas of cognitive approach for solving semi- structured problems.
\end{abstract}

\section{Introduction}

Processes occurring in the regional transport complex can be attributed to a wide class of problems of decision-making and management at a regional level. Problems of this type relate to semi-structured problems with a low level of accuracy of initial indicators and a qualitative form for describing the dependencies. Therefore, it is expedient to investigate this type of problems on the basis of application of various types of economic-mathematical models. One of these methods of optimization of control systems is a graph-analytical one, which allows describing main relationships with the help of sign graphs. The effectiveness of application of this method in the area of optimization of the regional transport complex management system is determined, firstly, by its relative mathematical simplicity, which significantly reduces the high level of computational complexity, and secondly, by the low sensitivity to the level of accuracy of the initial indicators and the possibility of constructing models on the dependences of a qualitative order.

The graph-analytical method was widely used in technical sciences $[1,2,3]$ and only later it was used in other sciences $[4,5,6]$, where a specialist's "hand labor" is difficult to be fully automated.

Various factors of socio-economic life are closely interrelated and constantly influence each other. For each of them specific range of factors can be defined that have an impact on it. In our opinion, regional transport policy, socio-economic conditions, innovation and investment climate, etc., can be such factors for the RTC. In general, the mentioned factors have a qualitative nature [9-12].

\footnotetext{
* Corresponding author: guketlevUH@mail.ru
} 


\section{Graph-analytical method of the regional transport complex control system optimizing}

Let's present the basic principles of building a model of a regional transport complex management system (RTC) with the help of symbolic graphs in a matrix form. The method of constructing this model will be based on well-grounded algorithms from $[7,8]$.

Initially, basic elements, so-called system components, are defined. To study the methods of the RTC control systems optimization the following main components were determined that have the most effective impact on the RTC functioning:

$P-$ a component of the transport policy;

$C$ - a component of social and economical features of a region;

$N$ - a component of the regulatory support;

$I$ - an innovative component;

$D$ - a component of road and transport infrastructure supply;

$S$ - a component of information provision;

$F$ - a financial and investment component.

The interaction between these components is described by the elements located outside the main diagonal of a conditional matrix, and diagonal elements are represented by the above mentioned components. The matrix will be as follows:

$$
R T K[o]=\left[\begin{array}{ccccccc}
P & P C & P N & P I & P D & P S & P F \\
C P & C & C N & C I & C D & C S & C F \\
N P & N C & N & N I & N D & N S & N F \\
I P & I C & I N & I & I D & I S & I F \\
D P & D C & D N & D I & D & D S & D F \\
S P & S C & S N & S I & S D & S & S F \\
F P & F C & F N & F I & F D & F S & F
\end{array}\right]
$$

Conditionally, the presence of the effect of one component on another is indicated by an arrow between these components, for example $\mathrm{K} \rightarrow \mathrm{F}$.

In accordance with $[6,8]$ in the next step the interaction matrix is coded according to the level of importance for the study (the degree of importance was also determined on the basis of expert assessments): if it is important, then the code is 1 , otherwise the code equals 0 . (the $\mathrm{RTC}[c]$ Matrix, formula (2)). The RTC $[c]$ Matrix is put in correspondence with the following digraph (figure 1).

In the third stage, a qualitative coding is performed: with positive influence of one component on the other unit is taken with "+" sign, and, when the influence is negative- with the "-." sign. (The RTC [q] matrix, formula (2)).

The fourth stage is based on expert estimations at a three-point grading scale: formally weak influence is estimated at one point, informal-average - at two points, and informally strong - at three points.

We obtain an economic-mathematical model in the form of a weighted oriented graph with data at the vertices which is similar to the well-known V. Leontiev's model of the interlacing balance [8], but in our model only qualitative factors are mainly used. 


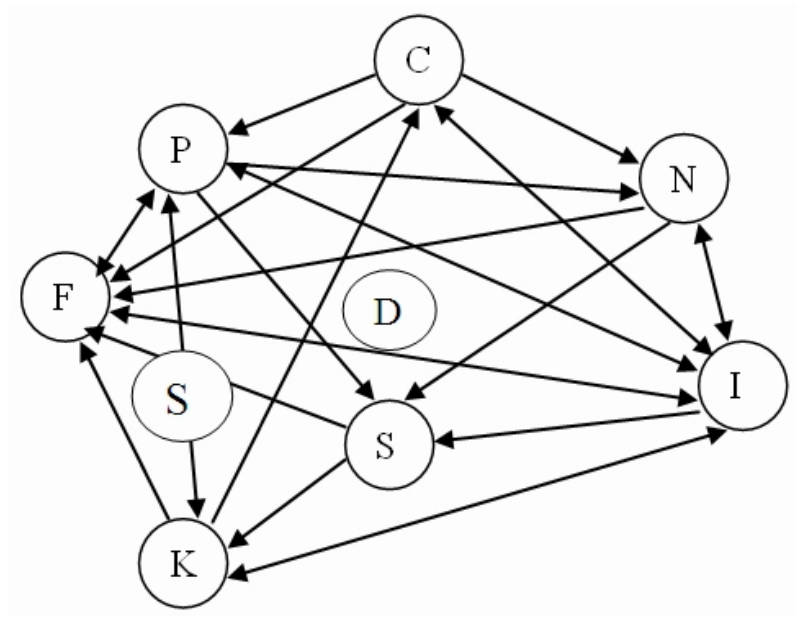

Fig. 1. Directed graph of the relationship matrix.

For its creation the opinions of expert commissions were used, and two matrices were compiled: one - according to the type of RTC [s] links, and the other - according to the quantitative estimation of RTC [v] (formula (2)). The RTC [v] matrix gives a binary estimation of the interaction schemes between the components. Each binary relation is estimated according to a corresponding point scale.

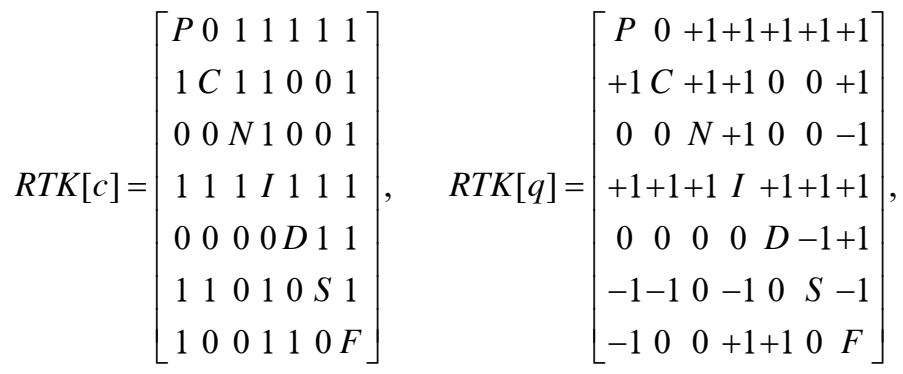

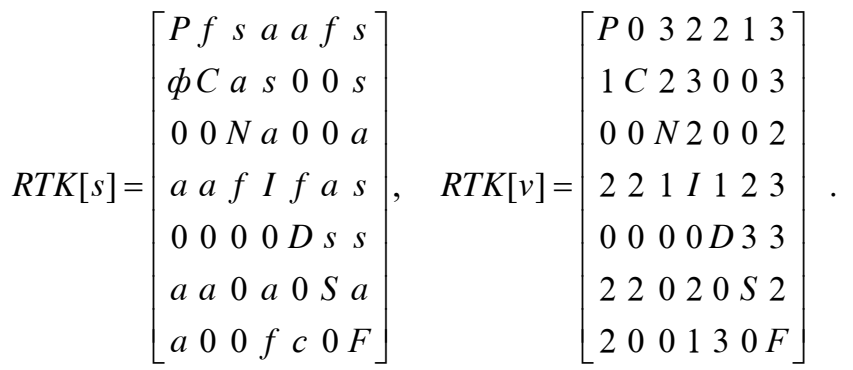

For example, a single-angle binary relation $\mathrm{P} \rightarrow \mathrm{N}$ has value of 3 due to the influence of regional policy on all components except the component $\mathrm{C}$. The influence of component $\mathrm{P}$ on $\mathrm{N}$ can be determined through the relations $\mathrm{P} \rightarrow \mathrm{I} \rightarrow \mathrm{N}$ which also has value of 3 points, but representing the sum of values at each edge of the angle with values of 2 and 1 . Consequently, the way $\mathrm{P} \rightarrow \mathrm{K} \rightarrow \mathrm{I} \rightarrow \mathrm{N}$ has value of $4, \rightarrow \mathrm{F} \rightarrow \mathrm{I} \rightarrow \mathrm{N}$ has value of 5 . Thus, there are various options of the schemes of influence of the components on each other, which, allow you to choose optimal interaction schemes between the components of the system.

At the fifth stage priority components are determined according to their level of influence in the chain of causalities noted in the RTC [c] matrix: The reason level (C) corresponds to 
the sum of the importance values in this row of the matrix, and the effect (Q) - to the sum of the values of importance in this column (Figure 2). In a specific example, the components of the components in the cause-effect system $(\mathrm{C}, \mathrm{Q})$ will be: $(5,4)$ for $\mathrm{P},(4,2)$ - for $\mathrm{C},(2,3)$ for $\mathrm{N},(6,5)$ - for I, $(2,3)$ for $\mathrm{D},(4,3)$ - for $\mathrm{S}$ and $(3,6)$ - for $\mathrm{F}$.

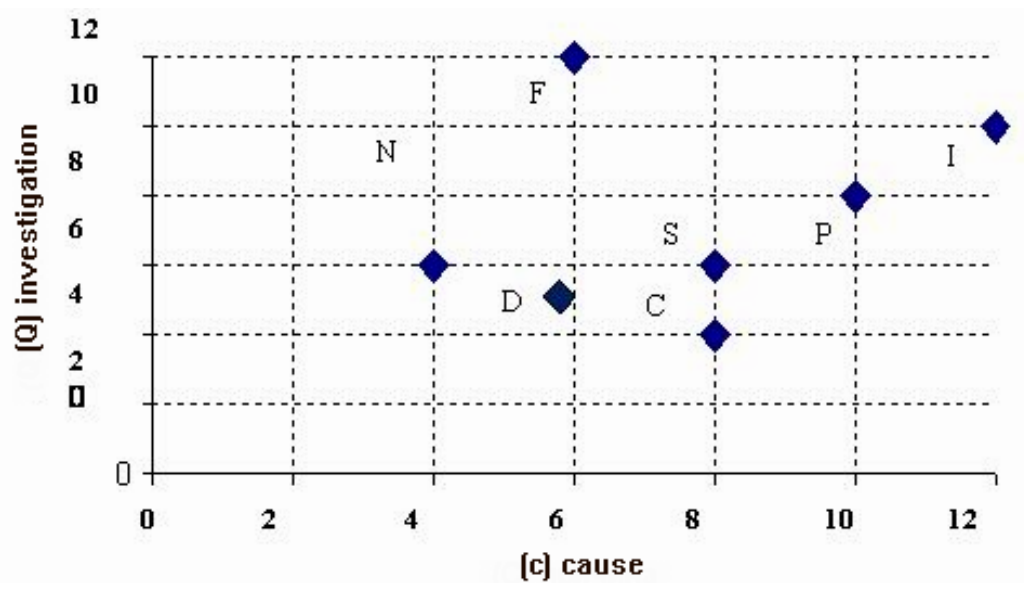

Fig. 2. Structure of causalities of the components of the RTC control system.

Figure 2 reflects the main structure of cause-effect relationships: the components I and $\mathrm{P}$ will be dominant, and the most dependent components are $\mathrm{N}$ and $\mathrm{D}$. Consequently, in the RTC management system the most important are components I and P, where the regional administration must concentrate its main actions on achieving the best results in the formation of its transport policy and financial and innovation support for the RTC. The most dependent components are that of regulatory and infrastructural support.

Now there is a possibility of constructing optimal schemes, under which the greatest influence of some components on others is formed, on the basis of which organizational and economic mechanism of the RTC management, which is the most acceptable for the region, is built. Certainly, there are many options for interaction schemes between individual elements of the system. This allows you to select schemes that have ways of interaction between two individual components of the system and describe them specifically.

For example, let's study all possible schemes of cause-effect relationships between the components $\mathrm{P}$ and $\mathrm{F}$ (way $\mathrm{P} \rightarrow \mathrm{F}$ ): $\{\mathrm{P} \rightarrow \mathrm{F}\},\{\mathrm{P} \rightarrow \mathrm{N} \rightarrow \mathrm{F}\},\{\mathrm{P} \rightarrow \mathrm{I} \rightarrow \mathrm{F}\},\{\mathrm{P} \rightarrow \mathrm{D} \rightarrow \mathrm{F}\},\{\mathrm{P} \rightarrow \mathrm{S} \rightarrow \mathrm{F}\}$, $\{\mathrm{P} \rightarrow \mathrm{N} \rightarrow \mathrm{I} \rightarrow \mathrm{F}\}, \quad\{\mathrm{P} \rightarrow \mathrm{I} \rightarrow \mathrm{D} \rightarrow \mathrm{F}\}, \quad\{\mathrm{P} \rightarrow \mathrm{I} \rightarrow \mathrm{S} \rightarrow \mathrm{F}\}, \quad\{\mathrm{P} \rightarrow \mathrm{D} \rightarrow \mathrm{S} \rightarrow \mathrm{F}\}, \quad\{\mathrm{P} \rightarrow \mathrm{N} \rightarrow \mathrm{I} \rightarrow \mathrm{D} \rightarrow \mathrm{F}\}$, $\{\mathrm{P} \rightarrow \mathrm{N} \rightarrow \mathrm{I} \rightarrow \mathrm{D} \rightarrow \mathrm{S} \rightarrow \mathrm{F}\}, \quad\{\mathrm{P} \rightarrow \mathrm{I} \rightarrow \mathrm{D} \rightarrow \mathrm{S} \rightarrow \mathrm{F}\}$ with grades corresponding to their values: 3, 6, $5,5,3,8,6,6,7,9,11,8$.

The scheme shows that the greatest effect can be achieved by the scheme $\{\mathrm{P} \rightarrow \mathrm{N} \rightarrow \mathrm{I} \rightarrow \mathrm{D} \rightarrow \mathrm{S} \rightarrow \mathrm{F}\}$ which provides the highest grades. Therefore, when creating a regional transport policy, priority should be given to creating appropriate regulatory and legal frameworks, developing algorithms for choosing optimal schemes for regulating impact on the system, creating a road and transport infrastructure and information support that will significantly improve the RTC's financial and investment attractiveness. Of course, financial and investment activity can be increased in a minimally short way $\{\mathrm{P} \rightarrow \mathrm{F}\}$, using only government funding and not attracting private capital, which is absolutely inefficient in market conditions.

\section{Results and discussion}


A distinctive feature of using the graph-analytical method is that it allows to determine the degree of influence of the reverse causality existing between the components. For example, by the reverse causality scheme $\{\mathrm{P} \rightarrow \mathrm{N} \rightarrow \mathrm{I} \rightarrow \mathrm{F} \rightarrow \mathrm{P}\}$ we can assess the effectiveness of the regional transport policy. Let's assume that local authorities plan to change the regulatory framework $\{\mathrm{P} \rightarrow \mathrm{N}\}$ in order to increase the level of innovative attractiveness in RTC $\{\mathrm{N} \rightarrow \mathrm{I}\}$, and due to the increase of innovative activity $\{\mathrm{I} \rightarrow \mathrm{F}\}$ to achieve the growth of financial investments. Thus, with a real increase in private investments at the output along the way $\{\mathrm{F} \rightarrow \mathrm{P}\}$, local authorities assess the level of effectiveness of the chosen transport policy [13$15]$.

Similarly, it is possible to analyze the interrelations in the constructed RTC management system and develop ideas for its adjustment. At the same time, we can compare information about a really simulated system, revealed empirically, with the information that the model gives in the same sphere of parameters. With small differences, the constructed model can be considered adequate.

\section{Conclusion}

Dynamic processes occurring in a complex socio-economic system of the RTC are difficult to model using a simple graphical-analytical method. Transition to the construction of a functional sign or graph is necessary $[3,8]$. But it can be difficult because of the difficulties in determining the parameters of these functions. Therefore, application of the graph-analytic method presented above is possible with some periodicity in time.

Thus, graphical-analytical method of the optimal RTC control system formation allows us to carry out a long-term analysis and to choose priorities in the development of various control schemes.

The proposed model is based on the ideas of cognitive approach for solving semistructured problems investigated at the Institute of Control Sciences of the RAS [8], but on the basis of other mathematical support.

It should be noted that, apart from the noted positive aspects, use of the graphical analytical method has certain drawbacks: first, its effectiveness largely depends on the quality of expert assessments; secondly, the number of paths that are subject to analysis increases with the increase in the dimension of the problem; thirdly, the lack of a software product that allows modelling in the framework of this method.

\section{References}

1. M.K. Bedanokov, N.G. Mashinina, Improvement of management of the transport services system in the region. Federal State budget educational institution of higher prof. education Maikop State Technological University, Maikop, Russia, P. 199 (2011)

2. V.P. Belokurov, E.N. Busarin, A.Yu. Artemov, S.V. Pustovalov, Passenger transportation management and its features. Bulletin of transport information, 5 (251), pp. 8-12 (2016)

3. Yu.Kh. Guketlev, E.Yu. Guketlev, Graphoanalytical model of urban passenger transport management system. Actual issues of innovative development of the transport complex / Materials of the 5th International Scientific and Practical Internet Conference, pp. 147-155 (2016)

4. Yu.Kh. Guketlev, Y.S. Tkacheva, E.Yu. Guketlev, Foreign experience of urban passenger transport development. New technologies, 4, pp. 27-32 (2016) 
5. Yu.Kh. Guketlev, Y.S. Tkacheva, E.Yu. Guketlev, Passenger transport in the social and cultural space of cities and regions. New technologies, 4, pp. 22-26 (2016)

6. Yu.Kh. Guketlev, A.S. Indrisov, N.G. Mashinina, V.V. Kondratenko, Programmatic method of the regional transport complex regulation system development. Regional economy: theory and practice, 9, pp. 26-30 (2008)

7. Yu.Kh. Guketlev, Regionalization as formation of territorial transport systems. New technologies, 1, pp. 92-95 (2012)

8. Yu.Kh. Guketlev, I.B. Akhunova, H.G. Gusaruk, E.Yu. Guketlev, Management of the regional transport complex: a textbook / - $2^{\text {nd }}$ ed., ext. - Maikop: MSTU Publishing House, P. 159 (2016)

9. N.I. Zlobina, G.A. Denisov, V.P. Belokurov, G.N. Klimova, Ways to improve the safety of urban passenger transport . University Science - 2016 theses of the reports of the International Scientific and Technical Conference in 3 volumes. Azov region State Technical University, P. 258 (2016)

10. V.A. Korchagin, A.N. Novikov, S.A. Lyapin, Yu.N. Rizaeva, Complex self-developing transport systems. The world of transport and technological machines, 2 (53), pp. 110116 (2016)

11. A.B. Kulev, A.N. Novikov, M.V. Kulev, N.S. Kuleva, Improving the efficiency of urban passenger transport. Information Technologies and Innovations in Transport / Materials of the 2nd International Scientific and Practical Conference, pp. 378-382 (2016)

12. I.A. Morozova, Sh. M.Tagirov, Analysis of transport infrastructure development in the regional economic complex. Bulletin of Makhachkala branch of MADI, 10, P. 226-230 (2010)

13. Takeo Yamada, Leslie R. Foulds, A graph-theoretic approach to investigate structural and qualitative properties of systems: A survey. Networks, 20, Issue 4, pp. 427 - 452 (2006)

14. A.O. Oni, A. Omolade, Graph-Theoretic Approach to Resolving the Accessibility and Site Selection Issues in Planning and Development. Mediterranean Journal of Social Sciences, 5(8), pp. 11-20 (2014)

15. A. Reiffer, M. Heilig, M. Kagerbauer,P. Vortisch, Microscopic Demand Modeling of Urban and Regional Commercial Transport. Procedia Computer Science, 130, pp. 667-674 (2018) 